preparing these plans. The shorter-term traffic solutions should not be looked at in or by themselves, howevor, but should be viewed so far as possible in relation to parking policies, to the needs of environmental as well $u$ traffio management and to tho likely ultimate pattern of town roads. Together they constitute the broad approach to the problem of traflic in towns; in particular, any short-term proposals which would determine road widths or alignments for a long time ahedid should be carefully considered in this wider context.

The memorandum includes a report on a preliminary reconnaisance to identify the nature of traffic problems, the information available on traffic data, accidents and land-uses, and the extent to which further information is needed. This is followed by a section on mothods of taking traffic censuses, origin and destination surveys, surveys of public transport, measurements of speed, parking surveys and of collecting accident data. In the third section, the processing and presentation of survey information ready for some formulating scheme are considered, and in the fourth, the design of short-, mediumor long-term schemes to meet the needs of both traffic and road safety. The fifth section considers methods for comparing the advantages and disadvantages of alterna. tive proposals, including the economic assessment of road improvements, and, in the sixth soction, investigations needed to vorify the adequacy of the measures taken and to reveal any need for further measures aro discussed. Finally, the value of quantitative assessment of traffic problems and improvement schemes, the need to study and train engineers in the methods of meeting traffic requirements and to take advantage of now, or little-used, techniques are considered.
New methods of meeting traffic problems, such as new types of signal-controlled pedostrian crossings, "give way to traffic from the right" signs at roundabouts, the use of vehicle presence detectors, tidal traffic working and area traffie control, are likely to come increasingly into use as their possibilities are explored, with also increasing application of pedestrian segregation, channelization, urban motorways, and grade-separated systems. Shortterm measures may offor much relief of congestion at little cost, and waiting restrictions, banning of right turns, or one-way systems often increase road capacity by 20 per cent or more. Improvemonts of 20 to 50 per cent can often be effected at signal-controlled junctions, by rephasing and simplifying the traffic pattern, by restricting certain movements, or by small carriageway widenings at the signal approaches, as well as through increasing use of the more flexible modern traffic signal controllers to meet peak-hour demands.

With medium-torm measures, the emphasis should be on junction improvements, provision of roundabouts, new signal-controlled junctions and widening roads, particularly at junctions or bottlenecks. In narrow streets lay-bys for buses or delivery vehicles can be of great value in promoting a freer flow. 'I'raffic engineering techniques can help longer-term moasuros which require programming in order of priority. In determining priorities and in designing various schemes for new or improved roads and junctions and general road layout, to meet the future requiromonts of a town, it is emphasized that in establishing environmental areas and freeing them of unnecessary traffic, the traffic on the primary road network will bes increased, and the network must therefore be designed to take heavier flows.

\title{
SOCIAL INFLUENCES ON MEASURED INTELLIGENCE
}

T HE Novernber issuc of Educational Research (8, No. 1) contains fivo separate papers on various aspects of the influence of social factors on the measured intelligence quotiont (I.Q.). Taken together, they are of outstanding public interest. One paper is entitled "Further Evidence on the Effect of Date of Birth on Subsequent School Performance", by R. Freyman, and is based on a study of: (a) 3,419 children born during 1952-55 from eight streamed junior schools in different parts of Middlesbrough; (b) 4,120 children born during 1953-55 from seven streamed secondary modern schools, four grammar schools and two other selective secondary schools; (c) 364 junior school children attending remedial reading groups; (d) 312 children reforred to the child guidance service; and (e) 156 children attending the day spocial school for educationally subnormal (E.S.N.) children. Among the children in streamed junior schools, of those born during the period Septomber to Decomber, 39.7 por cent were in $A$ classes, 25.8 per cent in $B$, and 22.4 per cent in $C$, while of those born in the period May to August, 28.2 per cent wore in $A, 36 \cdot 6$ por cent in $B$, and $43 \cdot 7$ per cent in $C$ classes. These differences were statistically highly significant, along with the finding that the percentage in the $A$ stream increased with length of schooling.

Similar results were obtained from all the children attending secondary schools. of those born during September to December, 36 per cent were in selective schools and 28.4 per cent in secondary modern schools, whereas, of the ones born during May to August, 32.3 per cent were in solcctive schools and 36.1 in secondary modern schools. Again, a larger proportion of younger than of older children obtained low and average marks.

of the children in remedial reading groups, 46.7 were born during May to August, and 27.8 per cent during January and April periods, a discrepancy which was wider still among those referred to the educational psychologist because of backwardnoss in reading. The children attending the local E.S.N. school produced less clearly cut differences.

From his survey, Freyman concludes that the date of birth exerts a significant influence on a child's school grading, and that at junior level, streaming in schools tends to perpetuate differences due to date of birth. The disadvantages of the children born during May to August wero greatest in those referred because of difficulties in reading; and "secondary psychological symptoms such as lack of confidence and emotional maladjustment were often displayed".

It might be thought that these discrepancies arise because children borm in September to December are almost 8 years old when transferred from infant to junior schools as compared with the 7 or 7 and 4 months age of thoso born in the summer. But in itself, that factor, although real, can be allowed for; it does not account for the whole of the difference, which seerns to be determ ined by some specific condition, not simply delayed mental development; and Freyman calls for a new educational deal for children born during the summer, which might include longer time in the infant school and more flexible forms of educational organization.

In his paper on "Date of Birth and Scholastic Pcrformance", D. A. Pidgeon is concernod with the same kind of theme whilo carrying the discussion somewhat further. He makes the point that children who have hac more schooling will have lenrned more and in examinations are likely to give better results; but in addition, children born in summor usually rernain the youngest in their group throughout the junior school, a situation which imposes additional stress. Supporting evidence comes from Sweden.

It is a moot point whether, as a whole, the innate intelligence varies as between childran born at different 
times in the year. This question can be approached only through tests, which at school age give results similar to those already indicated. To some extent it may be clarified through appropriate tests carried out on children of pre-school age. But at present, many children are handicapped for life through being born during summer months and having to fit into the teaching year.

Pidgeon thinks that the abolition of streaming would remove one obvious and distasteful effect, but "while classes consist of younger and older children, the younger may continue to suffer in other ways". To him, the only true solution would be the individualizing of learning, along with a change of approach from present class teaching methods.

In the next two papers, interest shifts to educational performance between different kinds of children and in different types of secondary schools. W. H. King writes on "Differences in Mathematical Achievement Related to Types of Secondary Schools and their Geographical Locations". This is part of a much larger study based on comparisons between children attending schools in South-East England and others in the twin cities St. Paul-Minneapolis, Minnesota. A special sampling technique was used on 58 secondary schools representing all the different English types, and in each the unit of testing was a complete form.

In addition to questionnaires completed by teachers and students, three standardized tests were used: Mathematics Test 1 by MacFarlane Smith; Co-operative Sequential Tests-Mathematics STEP Test; and Raven's Progressive Matrices, 1956 edition. 3,134 children had scores on all three tests. Taking grammar, technical, secondary modern, and comprehensive schools in order, on Raven's test the mean scores were $49 \cdot 81,49 \cdot 72,44 \cdot 18$ and $45 \cdot 76$; on the $S T E P$ test, $37 \cdot 13,33 \cdot 44,24 \cdot 22$ and $26 \cdot 62$; and on the Maths 1 test, $83 \cdot 83,80 \cdot 28,55 \cdot 69$ and $57 \cdot 96$. Contrasting pairs of schools were also tested. On Raven's test the differences were not great but they were very marked with the other two, particularly the Maths 1 test.

In all these tests, the grammar school scores were the least variable, the differences widening progressively in secondary modern, technical, and comprehensive schools, and especially because of wide differences in mean scores, with considerable overlap between schools. It is clear that comparisons between mean scores in different types of secondary schools are of little value. Nevertheless, it was estimated that two-thirds of the high ability group came from grammar schools, while three-quarters of children of low ability were to be found in secondary modern schools. Still, "no one type of school has a monopoly of students in the high or low ability category".

In his conclusions, King directs attention to the very wide gap in scores between children in grammar and technical schools on one hand and secondary modern ones on the other, suggesting that the causes, motivations and levels of aspiration are not linked solely with differences of ability. These points urgently need attention; and the research has uncovered a problem of raising the achievements of the lower ability group in secondary modern and comprehensive schools without lowering it in grammar and technical schools. Particularly in the two mathematical tests, the findings were disappointing. Clearly, in relation to mathematics, the minds of many children are not being fully stretched. That conclusion may also apply to the United. States public schools with which the project is linked, where the students' scores again are relatively low.

King does not go on to discuss the social influences which might account for these differences. Instead, in a paper on "Meritocratic and Social Class Selection at Age Eleven", D. F. Swift approaches intelligence tests on school children from another angle. Drawing on the work of Floud, Banks and Halsey, he states that "in developing industrial societies, the educational system is replacing all others as an avenue of social mobility". His own research was carried out in the North of England, covering 132 families, and was designed to compare the attitudinal environment of the home with the ability of the children, making use of the $11+$ allocation procedure. The group under test represented a 10 per cent sample of all families in two Local Education Authority Divisions. Taking parental occupational groups, under the State Sehool Sampling Frame, I to VI, the 278 children who passed at age eleven plus were distributed in the order $108,78,62$, 13,13 and 4 , while by contrast, of the 922 children who failed, the corresponding figures were $98,120,290,44$, 157 and 213. Grouped by social class, 60 per cent of the middle class children passed, and 40 per cent failed, as against 11 per cent of working class who passed while 89 per cent failed. Again, middle class children had a mean score of 117 in verbal reasoning, 122 in English, and 117 in arithmetic, as against working class children, whose scores in these respective subjects were 100,103 and 101 .

On these results, ostensibly, the British ideal of equality of opportunity is being met, but present psychological knowledge recognizes the importance of motivation in test performance. Had borderline cases been taken into consideration, one-half of the working class children but only one-tenth of those of middle class would have been rejected for grammar schools.

Swift then goes on to consider what should be the basis for the 'meritocratic' system of selection. It seems to him that because of similarities between value-orientations of middle class and school life, "the use of middle class children as a base group is justified"; but any scheme for the organization of talent-producing institutions would need to be based on research covering large numbers in many different areas. And it is important to bear in mind that perspectives must be concerned with the contribution of education to allocations in society, for which the first step would be to establish how far education was important in the total process of meritocratic or social class selection.

The longest and most far-reaching paper is by $O$. Ferron, on 'The Test Performance of 'Coloured' Children". $\mathrm{He}$ is working at Najala University College, Sierra Leone. He draws on the findings of many surveys of which the following may be taken as representative. Many early I.Q. tests in the United States tended to show that white children were superior to Negro and Red Indian ones and that children of North European stock were superior to those coming from South Europe. In 1926, Hirsch measured the I.Q. of immigrant children, and found that the mean score of British Canadians was 93.8, French 85.3, Negroes $84 \cdot 6$ and Portuguese $82 \cdot 7$. But in the same year, Helmer devised tests which contained subject-matter relating closely to the life of Red Indians, in accordance with which when compared with them white children were definitely inferior. On the other hand, Rohrer attributed the low scores of Red Indians in other tests to such factors as differences in social and economic status, differences in cultural environment, language differences, differences in test motivation, and inaccuracies in estimating chronological age.

Another worker in the field was Pyle, who found that Chinese children attending public schools were superior to American ones in rote learning, but inferior in tests involving logical relationships and in speed of learning generally. Then, in 1930, the University of Hawaii published the results of testing 4,500 children in the United States and Hawail-where differences in social status between Chinese, Japanese, Portuguese, Puerto Ricans and Filipinos have been much reduced-which indicated that when differences in environmental opportunities are not too great, differences in intelligence performance could be expected to be correspondingly small.

Early work on African children produced results showing that they were markedly inferior to the Whites. For example, Fick, in 1939, concluded that Zulu children 
aged 10-14 were from four to five years behind children of European descent on American Army Beta tosts, and Oliver, on work initiated in 1932, concluded that in East Africa only 14 per cent of Africans reached or exceeded the European mean. But results like these stimulated interest in environmental factors, such as illiteracy among parents, and extremoly low standards among teachers in primary schools, together with the very poor equipment of native African homes.

Ferron gocs on to point out that in Africa the gap between white and non-whito children can be reduced by the use of non-language tests, but the cultural ways of life and patterns of child rearing are significantly different, as also are cultural modes and traditional attitudes; but he thinks that "it would be far more constructive to continue with the use of Western type tests, since African aspirations are in tho direction of a western technological civilization". Indeed, comparisons between British and African test performance can be justified in that they show where emphasis should be placed in the matter of environmental deficiencies. As a result of an investigation which he began in Freetown in 1960 and completed in Zaria in 1964, he concluded that the test quotient of an African group is to a large extent dependent on the degree of assimilation of western culturo. Ho emphasizes that for African children, "the difficulty of passing from one world to another as the child grows older, of living in two worlds simultaneously, and of acquiring the newly imposed and rather unrealistic symbols of success and status, represents a struggle for survival with which the biological struggle of the survival of the tittest can bear no comparison, for oven those who survivo the former appear to be emotionally, psychologically and intellectu. ally maimed for life". But he doos not despair of the future, although until a simultaneous attack is made on many fronts, progress will continue to be slow; and the effort should be spread over the whole educational field, from birth onwards. In this campaign, the chief impediments at the present time appear to him to be found: (a) in the school, because of a mechanical approach to teaching in the early years particularly, in the teacher's relative lack of facility in the use of the English language, through discouraging the child from asking questions and exploring his environment, sovere and capricious corporal punishment, along with mental rigidity, and an attitude of dogmatic authoritarianisin; $(b)$ in the homo, because of birth injuries and incidence of subsequent malnutrition and disease, certain early child-rearing practices that are in the nature of traumatic experiences, the nature of the emotional relationships between adults and children, illiteracy, mainly of the mother, and lack of appropriate stimulation in the home and neighbourhood environment, and lack of definito teaching on the part of older children and adults; and (c) in government action through lack of proper physical surroundings in home and school, and relative lack of stimulation from mass media of instruction.

Because colour prejudico and discrimination against coloured people are not so severe in Britain as in the United States, Forron thinks that a useful link and exchange of ideas might be established between research workers in Britain and in other parts of the world.

R. Weatherall

\title{
EMISSION BAND SYSTEMS OF $\mathrm{Ag}_{2}$ PRODUCED IN DISCHARGE
}

\author{
By Prof. CHOONG SHIN-PIAW, WANG LOONG-SENG and LIM YOKE-SENG \\ Department of Physics, Nanyang University, Singapore
}

\begin{abstract}
N recent years, use has been made of King's furnacn by 1 several workers in their studies of the band spectra of silver and other high boiling-point metals. As a result, five band systems of the diatomic silver molecule havo now been found. They are: (1) the systom $\lambda \lambda 4100-5200$ first studied by Ruamps ${ }^{1}$ in emission, and later by Kleman and Lindkvist ${ }^{2}$, both in emission and in absorption; (2) the system $\lambda \lambda 2750-2850$, by Ruamps ${ }^{3}$ and by Joshi in absorption; (3) the system $\lambda \lambda 2640-2700$, by Ruamps and by Maheshwari ${ }^{8}$ in absorption; (4) the system $\lambda \lambda 2560-2620$, by Ruamps in absorption; (5) the system $\lambda \lambda 2460-2560$, by Ruamps and by Maheshwari also in absorption. According to the vibrational analyses of these workers, these five band systems have a common lower electronic state of vibrational frequency $192.4 \mathrm{~cm}^{-1}$. It is generally believed that this lower state is the groundstate of $\mathrm{Ag}_{2}$. More recently, two of us ${ }^{8}$, making use of quartz absorption tubes in thoir investigations of the atomic and molecular spectra of silver, were able to detect the visible band system at as low a temperature as $1,100^{\circ} \mathrm{C}$.
\end{abstract}

Following our work on the absorption spectra of silver, attempts havo bcen mado to obtain emission band systems of the metal in discharge. This discharge tube was made of fused quartz. It was composed of a central stom of length about $20 \mathrm{~cm}$ and bore of $8 \mathrm{~mm}$, two shorter and larger ond stems with fat windows, and two sido-tubos enclosing cylindrical aluminium electrodes of rather great heat capacity. After having introduced a few decigrams of spectrally pure fine grains of silver through a detachable window of the stem and having distributed thern evenly along the central stem, the discharge tube was set along the collimator axis of a Hilger medium-size quartz spectrograph. Tho contral stom was then wound about with a nichrome heating coil, and wrapped in turn with asbostos cloth, so that its temperature could be raised electrically for vaporizing the silver therein. A platinum-platinum rhodium thermocouple, previously attached to tho side of the central stem, served to indicate the temperature during heating. In performing an experiment, the discharge tube was connected to a pumping and feoding device for introducing pure neon at a pressure of about I $\mathrm{mm}$ of mercury which served for carrying an electric discharge. Preliminary tosts showed that: (1) the temperature of the central stem should bo raised to $1,100^{\circ}$ $\mathrm{C}$ and preforably to $1,200^{\circ} \mathrm{C}$ to get sufficient amounts of silver vapour for the discharge; (2) the side tubes, in which electrodes were enclosed, should be surrounded by solid carbon dioxide in order to get rid of the troublesome $\mathrm{OH}$ bands in the emission spectrum; (3) the average life of the heating coil was about $6 \mathrm{~h}$ at $1,110^{\circ} \mathrm{C}$, but it rarely exceeded $2 \mathrm{~h}$ at $1,200^{\circ} \mathrm{C}$. A high-tension transformer furnishing a power of $150 \mathrm{~W}$ was used to run the discharge tube. Exposures ranging from 5 to $20 \mathrm{~min}$ were found sufficient to record the band spectra on Ilford ' $H P 3$ Hypersensitive Panchromatic' plates. Iron arc served as tho comparison spectrum.

Under our experimontal conditions, six emission band systems attributable to the diatomic molecules of silver have been found. Five out of the six systems are proviously known in absorption, and one of them also in thermal emission. The new system is situated in the region $\lambda \lambda 3150-3630$. Vibrational analysis of the old and new systems reveals some interesting and important facts.

Visible system $\lambda \lambda 4100-4700$. About thirty bands have been observed in the region $\lambda \lambda 4100-4700$, and they are all degraded to the red. Most of the bands are found to group into well-marked sequences. With the disper. sion used, which was about $50 \AA$ per millimetre in this 